\title{
Chordal replacement: future surgical gold standard or first-line option as bridge to definitive therapy in primary mitral regurgitation?
}

\author{
Thilo Noack, Michael A. Borger \\ University Department of Cardiac Surgery, Heart Center Leipzig, Leipzig, Germany \\ Correspondence to: Michael A. Borger, MD, PhD. University Department of Cardiac Surgery, Heart Center Leipzig, Struempellstrasse 39 , 04289 \\ Leipzig, Germany. Email: michael.borger@helios-gesundheit.de.
}

Submitted May 25, 2020. Accepted for publication Jul 03, 2020.

doi: 10.21037/acs-2020-mv-22

View this article at: http://dx.doi.org/10.21037/acs-2020-mv-22

Surgical mitral valve (MV) repair is the recommended technique for treatment of severe primary mitral regurgitation (MR) (1). The first systematic approach to MV repair was introduced by Alain Carpentier in 1969 and the continual evolution of this technique has led to excellent long-term outcomes over the past decades (2). Carpentier's principles of successful reconstructive valve surgery were, namely: (I) preserve or restore full leaflet motion; (II) create a large surface of coaptation; and (III) remodel and stabilize the entire annulus. Future modifications of his initial described technique resulted in the MV repair being performed in many more cases and in more complex valvular anatomy (3). The evolution of MV repair of degenerative MR has trended towards less tissue resection, evolving from quadrangular resection with sliding plasty to triangular resection, to folding plasty and finally, to no tissue resection whatsoever, via chordal replacement $(2,3)$. Regardless of the amount of tissue resection performed, current MV repair strategies recommend the use of an annuloplasty ring or band to remodel or stabilize the mitral annulus.

Chordal replacement via polytetrafluorethylene (PTFE) sutures placed between the papillary muscles and the free edge of prolapsing segments in degenerative MR was first introduced by Frater in 1983 (4). This technique offers a potentially physiological MV repair, with PTFE sutures that are covered by a fibrous sheath within weeks of insertion (5). von Oppell and Mohr described the implantation of four pre-formed Gore-Tex loops (W. L. Gore, Newark, DE, USA) to simplify surgical chordal replacement during minimal invasive MV surgery (6).
Holubec and colleagues stated that non-resection techniques are associated with: (I) preserved leaflet mobility; (II) larger surface of coaptation; (III) minimal changes to the annular geometry; and (IV) implantation of larger prosthetic annuloplasty rings, when compared to classical Carpentier resection techniques (2). These conclusions were based on observations of improved leaflet kinematics, more physiological coaptation length and lower pressure gradients, which are mainly caused by larger MV orifice area and the implantation of larger annuloplasty rings, compared to resection techniques (2).

One of the main advantages of artificial chord implantation is their versatility. PTFE chordal replacement can be applied to almost any stage of degenerative MR including fibroelastic deficiency, single and bileaflet prolapse, and advanced Barlow's disease. In addition, they can be used extensive repair for hypertrophic cardiomyopathy or endocarditis (7). There is clear evidence that MV repair without tissue resection and extensive use of chordal replacement can be performed safely with excellent long-term clinical results. Results from specialized Heart Valve Centers have revealed that 30-day mortality rates of $<1 \%$, 1-year survival of $>97 \%$, and 1 -year freedom from reoperation $>98 \%$ can be achieved (7).

One of the main challenges associated with NeoChord placement, however, is the determination of the adequate length of artificial chords for optimal physiological MV function post-repair (8). This is particularly challenging in patients with anterior leaflet prolapse, which is associated with higher rates of repair failure. Further, the prevalence of MR increases with patient age and most of them with 
symptomatic MR are older than 70 years and denied surgery (9). Previous investigation has shown that in the elderly cohort (mean age 76 years), the 30 -day mortality increases to $3 \%$, and 1 -year survival decrease to $75 \%$ after surgical MV repair (10). In the elderly and other patients with increased surgical risk, safe and less invasive interventions with low rates of intervention-associated morbidity and mortality could play a more important role than effectiveness of MV therapy with regards to long-term freedom from residual or recurrent MR.

Over the past decade, the ongoing evolution of transcatheter MV repair techniques has also encompassed mitral chordal repair, which emulates the surgical technique in a transcatheter, mostly transapical approach. By using transcatheter chordal repair, the interventionalist could correct the length of artificial chordae under physiological conditions, (i.e., on the beating heart under normal loading conditions), which is one advantage of this technique (7). Transcatheter chordal replacement allows treating patients with only leaflet disease without moderate or severe annular dilation. Therefore, these procedures are mostly performed in patients in the early phase of degenerative MR.

There are currently three devices which are available for transcatheter chordal replacement. The system that has been implanted the most is the NeoChord device (NeoChord, Inc., Minnetonka, MN, USA), followed by the Harpoon system (Edwards Lifesciences, Irvine, CA, USA) and ChordArt (CoreMedic, Germany) (7). Clinical studies of the NeoChord system showed very good clinical results in a highly selected patient cohort. In a multicenter observation study (mean age 68 years), procedural success defined as reduction of MR to mild or less was $97 \%$ and 1 -year survival was $98 \%$, with $84 \%$ freedom from major cardiac adverse events at 1-year post-intervention (11). The authors of this study pointed out that the technical success was markedly influenced by the complexity of MR. The best clinical results were achieved in isolated central posterior leaflet prolapse/flail (type A) followed by posterior multi-segment prolapse/flail (type B); anterior or bileaflet prolapse/flail (type C); and paracommissural prolapse/ flail or any type of disease with the presence of significant leaflet/annular calcifications (type D) (12). The decrease in technical success with increasing complexity of MR is the decisive limitation of this technique. Although the device is currently used only in patients without marked annular dilation. The combination of different transcatheter $M V$ repair techniques may be used for such patients in the future. Based on the abovementioned findings, transcatheter chordal replacement may be an option in patients with noncomplex primary MR with mild or less annular dilatation and no atrial fibrillation, provided that the MV anatomy is favorable.

There is currently an ongoing Heart Team discussion on whether transcatheter chordal replacement should be performed first and if it fails, MV surgery could be done subsequently. This is mostly the case if the decision making is in the "gray-zone" between surgical and transcatheter MV treatment (i.e., in patients who are at increased, but not prohibitive, surgical risk). The basic principle is to weigh the safety and effectiveness of a therapy in the treatment of degenerative MR. For this decision, the following criteria could be used for a Heart Team consensus: (I) assessment of underlying pathology and complexity of MR with definition of anatomical structures which should be treated; (II) definition of treatment goal (e.g., curative treatment, improving symptoms, bridge-to-reoperation); (III) determination of risk factors for patient safety (e.g., age, co-morbidities); and (IV) assessment of the effectiveness of the treatment option in relation to patient risk profile. This approach may allow patient-oriented and evidence-based decision-making for the treatment of degenerative MR including a fair discussion of all possible treatment options.

In summary, chordal replacement is an essential part in the armamentarium of surgical MV repair which allows a nearly physiologic $M V$ reconstruction and can be applied to almost any pathology and at any phase of degenerative MR. This technique represents the current and future standard of care in degenerative MR. Isolated chordal replacement transcatheter devices should be applied only in selected cases. Patients with degenerative MR and risk factors for surgery should be evaluated for MV intervention by a multidisciplinary Heart Team in a Heart Valve Center.

\section{Acknowledgments}

Funding: None.

\section{Footnote}

Conflicts of Interest: The authors have no conflicts of interest to declare.

Open Access Statement: This is an Open Access article distributed in accordance with the Creative Commons Attribution-NonCommercial-NoDerivs 4.0 International License (CC BY-NC-ND 4.0), which permits the non- 
commercial replication and distribution of the article with the strict proviso that no changes or edits are made and the original work is properly cited (including links to both the formal publication through the relevant DOI and the license). See: https://creativecommons.org/licenses/by-nc-nd/4.0/.

\section{References}

1. Baumgartner H, Falk V, Bax JJ, et al. 2017 ESC/EACTS Guidelines for the management of valvular heart disease. Eur Heart J 2017;38:2739-91.

2. Holubec T, Sündermann SH, Jacobs S, et al. Chordae replacement versus leaflet resection in minimally invasive mitral valve repair. Ann Cardiothorac Surg 2013;2:809-13.

3. Carpentier A, Adams DH, Filsoufi F. Carpentier's Reconstructive Valve Surgery. From Valve Analysis to Valve Reconstruction. 1st ed. Maryland Heights: Saunders Elsevier, 2010.

4. Frater RW, Gabbay S, Shore D, et al. Reproducible replacement of elongated or ruptured mitral valve chordae. Ann Thorac Surg 1983;35:14-28.

5. Zussa C, Frater RW, Polesel E, et al. Artificial mitral valve chordae: experimental and clinical experience. Ann Thorac Surg 1990;50:367-73.

Cite this article as: Noack T, Borger MA. Chordal replacement: future surgical gold standard or first-line option as bridge to definitive therapy in primary mitral regurgitation? Ann Cardiothorac Surg 2021;10(1):167-169. doi: 10.21037/acs2020-mv-22
6. von Oppell UO, Mohr FW. Chordal replacement for both minimally invasive and conventional mitral valve surgery using premeasured Gore-Tex loops. Ann Thorac Surg 2000;70:2166-8.

7. Savic V, Pozzoli A, Gülmez G, et al. Transcatheter mitral valve chord repair. Ann Cardiothorac Surg 2018;7:731-40.

8. Neely RC, Borger MA. Myxomatous mitral valve repair: loop Neochord technique. Operative Techniques in Thoracic and Cardiovascular Surgery 2015;20:106-23.

9. Mirabel M, Iung B, Baron G, et al. What are the characteristics of patients with severe, symptomatic, mitral regurgitation who are denied surgery? Eur Heart J 2007;28:1358-65.

10. Seeburger J, Falk V, Garbade J, et al. Mitral valve surgical procedures in the elderly. Ann Thorac Surg 2012;94:1999_ 2003.

11. Colli A, Manzan E, Aidietis A, et al. An early European experience with transapical off-pump mitral valve repair with NeoChord implantation. Eur J Cardiothorac Surg 2018;54:460-6.

12. Colli A, Manzan E, Besola L, et al. One-year outcomes after transapical echocardiography-guided mitral valve repair. Circulation 2018;138:843-5. 